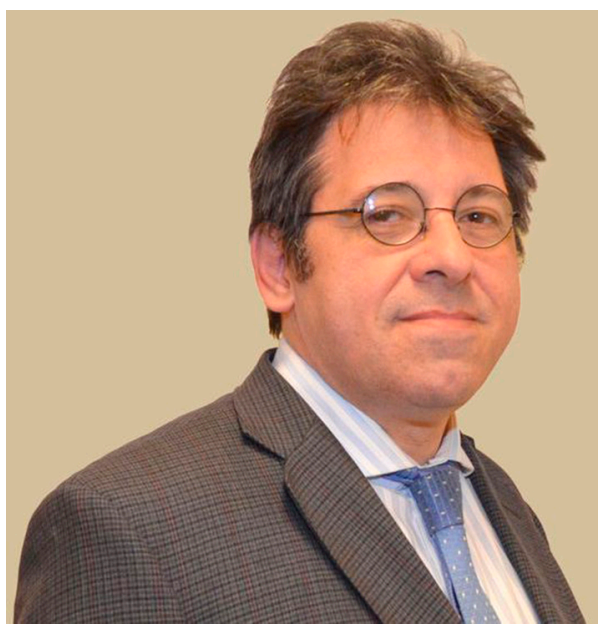

\title{
Extrañando a Raúl Raúl A. Borracci (1958-2021)
}

Como Presidente de la SAC, sentí la necesidad de escribir estas líneas para homenajear a Raúl a quién había conocido hace poco tiempo.

Comencé a interiorizarme en su trayectoria y me encontré con un Director de la Revista Argentina de Cardiología, que era cirujano cardiovascular, Doctor en Medicina, profesor Adjunto de Bioestadística, Magíster en Biología Molecular e Ingeniería Genética y Licenciado en Sistemas. Interesante e inusual encontrar una personalidad con inquietudes tan diversas.

Luego revisé sus publicaciones y me encontré con que Raúl nos ilustraba sobre temas de cirugía cardiovascular, sobre el impacto futuro de la feminización de la medicina en la Argentina y acerca de cómo "Evaluar y escribir un artículo científico", entre otras de sus numerosas publicaciones.

Comencé mi gestión reuniéndome con representantes de cada área SAC y el 11 de febrero nos encontramos con Raúl vía Zoom, para hablar de los proyectos de la RAC. Nos mostró una serie de métricas, tiempos de recepción a la aceptación de los artículos, hablamos de oportunidades de mejora, de la posibilidad de contar con una página web propia de la revista, de los nuevos intentos de indización de la RAC, de las próximas publicaciones, y de proyectos y más proyectos.

Luego me acerqué a quienes lo conocieron y me hablaron de su bondad, generosidad y compromiso en cada uno de los desafíos que encaraba. Sus compañeros de residencia lo recuerdan como una persona sincera, no egoísta, abierta, generosa, siempre dispuesta a enseñar. Otros me hablaron de un muy buen cirujano, muy preocupado por sus pacientes. Otros de su pasión por los números, y lo recordaban llevando libros de matemática.

Me queda la sensación de que perdimos a una persona increíble, estimado por sus colegas, equipo de trabajo y pacientes.

Siempre será un ejemplo a seguir

Alejandro R. Hershson

Presidente Sociedad Argentina de Cardiología
Como tantos otros colegas de la Sociedad Argentina de Cardiología (SAC), compartí inolvidables momentos con el Profesor Dr. Borracci, por su paso como Director del Área de Investigación, por el Comité de Bioética y en la Revista Argentina de Cardiología, donde dejó su marca en cada lugar.

Personalmente, pude percibir su alegría hace 3 años por su flamante cargo de Jefe de Cirugía Cardiovascular del Hospital Alemán. Era nuestro rencuentro, esta vez más cotidiano, y es a partir de ese momento que sobrevino la generación de un inmenso número de proyectos, muchos concretados, tanto asistenciales, integrativos de los distintos servicios (Cirugía Cardiovascular, Intervencionismo y Cardiología), sueños y trabajos sobre educación médica, montañas de datos e ideas para la investigación. Imagínense lo que fue convivir con un fuera de serie: un experto cirujano cardiovascular, pero también experto en Investigación Clínica, en Docencia Médica, en Estadísticas e Inteligencia Artificial, entre otras tantas actividades e inquietudes, y además descubrir al Raúl dentro del Profesor, sensible y cordial con los pacientes, quienes se sentían contenidos y confiados 
en sus manos. Equilibrado con sus pares, logramos también compartir con él vivencias personales, conteniéndome a mí mismo como persona.

Se transformó en padre adoptado por los residentes de Cardiología y los becarios de Cirugía Cardiovascular, un mentor colectivo: estimuló la vocación por la investigación, exigiéndoles dedicarse a la escritura de publicaciones, nacionales e internacionales. Con los cardiólogos jóvenes mantuvo también un vínculo cálido, insistiendo en la necesidad de su superación científica y profesional y el progreso en sus membresías de la SAC: mantener siempre la vara alta.

Generoso, irónico, incansable...polifacético. Un jugador diferente, de esos que recorren toda la cancha (y juegan bien muchos deportes), con solvencia científica, técnica y una voracidad inconmensurable por conocer...por compartir lo que sabe y sumar gente para desarrollar ese hallazgo.

"¿Cuándo vas a crecer, (epíteto afectuoso).....?", "ite vas a quedar llorando?....vos tenés que seguir siempre adelante, estudiar, publicar, el resto no te tiene que importar", "isabés algo de difusión de tecnologías sanitarias?, ¿de bioética?, ¿de redes neuronales?....... de fractales?" Todas esas preguntas me fueron formuladas por Raúl Alfredo Borracci con respeto, afecto y calidez. Tomé la costumbre de anotar lo que hablaba con él desde el año 2000. La pregunta, como modo sistemático de impulsar a los colegas más jóvenes fue una de sus características que más me movilizaron. Y me

¿Por qué un cirujano cardiovascular dirigía una revista orientada a cardiólogos en la Sociedad Argentina de Cardiología? La respuesta es simple, porque Raúl Borracci era extraordinario, un distinto, un profesional como nunca conocí. Dotado de una inteligencia suprema y una curiosidad insaciable, solamente él era capaz de llevar a cabo proezas que otros nunca ni siquiera imaginaron.

Yo lo conocí hace mucho tiempo cuando llegó al área de investigación donde yo llevaba años trabajando, en cuanto llegó su sola presencia removió el avispero. Él poseía esa incapacidad de pasar desapercibido. Tiempo después él mismo me convocó a la revista, la misma que va a publicar estas palabras de despedida. Así de caprichosa es la vida. Su súbita partida me dejó grogui, sin reacción, como un boxeador cansado que recibe su última trompada.

Raúl tenía la costumbre de expulsarte de tu zona de confort hacia áreas cubierta de arenas movedizas.
Lo que nos ha dado fue tanto, que el vacío actual es indescriptible, inmensamente desgarrador.

Honrémoslo como lo que fue: un compañero y amigo, colega societario, esposo y padre sin igual.

Un ser humano extraordinario. Generoso como muy pocos, con la generosidad de los grandes.

Raúl, le doy gracias al destino, por haberme dado la oportunidad de haber sido una pequeña parte de tu andar, sobre todo, en estos últimos e intensos años de tu vida.

\section{Claudio Higa}

consta que muchos somos los que tuvimos la fortuna de cruzarnos y aprender a superarnos de su mano... una mano que no arrojaba sombras, sino que te hacía subir un escalón e iluminaba. Ese sí es un rasgo de una persona infrecuente que crece con los demás y no a sus expensas.

"A mí lo que más me gusta es el método, lo demás pasa rápido....̇ite acordás que los betabloqueantes estaban contraindicados en la insuficiencia cardíaca?", "no hay que leer libros que tengan menos de 150 años". Dos de sus definiciones taxativas (quirúrgicas, diría) sobre su costumbre de buscar la esencia de las cuestiones y no los aspectos superficiales.

Las palabras nunca alcanzan.

Gracias, Raúl, iiiya nos volveremos a ver!!!

Mariano Giorgi

Él tenía la llave para hacerte intelectualmente mejor, sin ningún tipo de interés personal, excepto que desempolvaras tus ideas. Siempre te hacia re calcular el rumbo de tus proyectos y llevarte hacia el extremo de tus posibilidades.

Cada encuentro con él era un aprendizaje y yo percibía mi transformación con cada reunión. Quizás esa es la razón por la cual muchos lo lloran. Las personas como él no abundan por estos claustros. Desde que me enteré de su desdicha, las palabras para despedirlo se me atragantaron en el alma y sentí la necesidad de escribir estos párrafos porque es mi forma de mostrarle toda mi admiración y gratitud. Me gustaría creer que en algún lado voy a volver a verlo, en lugar de albergar falsas esperanzas prefiero decirle: GRACIAS POR TODO. Voy a intentar hacer pie en esas arenas movedizas donde solías empujarme.

Darío Di Toro 
Conocí a Raúl Borracci a fines de la década del 90; él era Cirujano Cardiovascular en la Clínica Bazterrica, yo uno de los médicos de guardia de la Unidad Coronaria. Nuestro contacto era allí escueto, regido por la urgencia de la asistencia del paciente crítico. Pero, un par de años después, coincidí con él en este río incesante y caudaloso que es la SAC. Recuerdo bien nuestra primera tarea conjunta, él Director del Área de Investigación, yo Secretario. Ya entonces me llamaron la atención su conocimiento de la materia, y su capacidad ejecutiva. Raúl sabía mucho, muchísimo, de Metodología y Estadística; Raúl se ocupaba de la Dirección con disciplina y precisión quirúrgica. Pero si tuviera que decir dónde conocí verdaderamente a Raúl, fue en el seno de la Revista Argentina de Cardiología. Lo vi como miembro del Comité Editor, como Director Asociado, como Director a secas. Y mi admiración creció, porque a las ciencias sumaba las artes: era un lector consumado de literatura clásica, de griegos y romanos (hay que leer libros que hayan superado el paso del tiempo, decía); sabía de historia, de música clásica, de filosofía. A la hora de juzgar los trabajos que llegaban a la Revista para ser evaluados Raúl sumaba a la crítica que no deja pasar nada, la actitud del que luego de señalar los errores se pone a enmendarlos, para hacer publicable el envío. Corregía tablas, hacía análisis estadístico, hermoseaba la redacción. Editaba los trabajos de los demás, y no dejaba de producir los suyos propios. Daba la impresión de no detenerse nunca; perder el tiempo era algo imposible para su naturaleza. Difícil no pensar en él como en un sabio del Renacimiento, de múltiples saberes, pero reconcentrado, alejado de la exposición pública y de la vanidad. En los últimos tiempos fungimos como Director de la Revista él, como Director Adjunto yo, como 20 años antes en Investigación. Y solo puedo decir que acá en la Revista lo extrañamos mucho y no dejamos de nombrarlo, y que sufrimos tanto que no hayamos podido trabajar más juntos, y que a la distancia física que nos imponía la pandemia se haya sumado esta otra, odiosa e irreversible. Y solo nos consuela pensar en un Raúl que, recostado en sus libros y su música, sigue leyendo, enseñando y pensando.

Jorge Thierer

Director Adjunto de la Revista Argentina de Cardiología 